\title{
Looking, Listening, and Moving
}

\author{
MUSIC AS A PROBLEM
}

Taiko is music, noise, visual spectacle, corporeal knowledge, and an archive of Asian American hope. It exceeds all these categories in some ways, but it is also subject to the many binary ideologies maintaining mind/body and music/dance as separate. The spectacle of taiko is shaped by powerful ideologies even as it sometimes challenges them.

The ephemerality of music poses a series of analytical challenges. Put simply, sound doesn't stand still: it moves through time. The sound of music is a moving presence that refuses to be pinned down for examination or revisitation. What can be examined are representations of sound-notated music or recordings, for instance-and there are many, many ways to analyze or to interpret those objects; indeed, entire fields are devoted to those projects (e.g., "music theory"). But the thing itself- "music"-is slippery, fleeting, and a significant ideological problem for ethnomusicologists (Wong 2014, 347-49).

"Music" is especially vexing for ethnomusicologists (as compared to historical musicologists, composers, or music theorists). ${ }^{1}$ Ethnomusicologists study sound as culture: we approach music as part or even constitutive of culture. ${ }^{2}$ (Musical) Sound is inextricably embedded in everything else that makes up culture and society. Some ethnomusicologists choose to focus on music as sound alone-that is, they spend their careers focused on the notes, the sounds, and trying to understand the relationships between rhythms, melodies, repertoires, and the like-but such ethnomusicologists are presently few in number. Most of us end up considering far more than the sound of music: we tend to believe that music makes sense only if you understand its relationship to political structures, religion, history, gender and sexuality, local and global economies, environment, social aesthetics. One might ask why ethnomusicologists seem concerned about so much besides the music. Ethnomusicologists are essentially anthropologists who study music, so we regard music as more than notes or sound: we understand it more broadly 
as performance, or as part of a range of expressive behaviors that are beautifully and exuberantly difficult to contain. As the ethnomusicologist Matthew Rahaim $(2012,1)$ asks, "What do we miss if we reduce music to sound?"

I have often not addressed formal musical structures, for instance in my scholarly work on the musics of Thailand and Asian America (Wong 2001, 2004). I am deeply distrustful of traditional music analysis, even though I know my sweeping generalization ignores the spectrum of possibilities presented by the field of contemporary music theory. I'm not alone in my uneasiness. The music theorist Fred Maus (2003) writes that music analysis sets up an opposition between "composition versus performance, music itself versus experience, structure versus embodiment." Taiko is a profoundly corporeal practice, yet taiko players are inexorably shaped by the aesthetic ideology that makes it possible to isolate the music from the rest of the sensorium, even when we generate a rhythm entirely shaped by how we want to swing our left arm in that phrase. The things I want to understand about taiko music are fundamentally at odds with the principles and ideologies of music analysis. ${ }^{3}$ My work has been vulnerable to the criticism that I don't address the music itself. Naturally, I am profoundly affected by musical sound, but the music itself is never just the sounds or the notes. Taiko forces me to address musical sound because it is that and so much more. So the challenge is how we can address musical sound without activating all the old moves that objectify it.

Taiko is noise as well as music. While this is true of all music, percussion more easily spills over from one social category to the other. Percussion is notoriously difficult to record because it "goes into the red" - that is, the attack and fast decay create a sound signal marked by clipping, the distortion that occurs when an amplifier is overdriven. These technical and acoustic properties are also wonderfully metaphorical. Noise is part of percussion's radical potential. Caroline Polk O'Meara $(2013,15)$ writes that "noise has a dual status as a category at once inside and outside of musical systems of knowledge." The French and French Canadian tradition of casseroles - street protest percussion featuring pots and pansis almost too synecdochic (Sterne 2012). I am certain audiences and performers are so thrilled by outdoor percussion traditions like samba, samulnori, and taiko because these powerfully activate the sound-body-environment relationship. The uncontrollable spread of the sound through bodies and neighborhoods suggests something a bit dangerous even as we delight in its careful arrangement into rhythms. As an ethnomusicologist I won't offer an essentialized theory of percussion, since all percussion and indeed noise, like all politics, is local. Avant-garde twentieth-century musics intentionally driven toward noise were often exploring futurist modes that rearranged the relationship between the body and agency, subjectivity, and experience. Noise has long played a key role in popular musics, and rock as a sprawling family of genres has long featured noise, from overloaded electrified timbres to noise rock as a genre. Indeed, O’Meara (2013, 14-15) argues that noise rock was a strategy to deconstruct and remake the rock tradition by deliberately rejecting any stable set of authoritative practices, but she also notes 
that noise as an intervention is constantly at risk of being reabsorbed as simply a different kind of order. Similarly, Kenneth Igarashi (1997) has explored how certain traditions of free improvisation are continually resituated as noise, and how noise as an intentional genre developed accepted practices in the late 1970s and early 1980s in New York City and the San Francisco Bay Area. Audiences, musicians, and sound engineers have complicated learned processes for identifying noise, filtering it out, or rejecting it. As Pamela Nash and Kevin Malone (2000, 105) note, "Noise is ever-present in the physical action of making and recording music. Players and listeners are taught to filter it out, composers pretend it doesn't exist, and recording engineers strive to reduce it in their medium."

Taiko is not explicitly conceived as noise by anyone I know, but its disciplined tumult is key to its affective hold over practitioners and audiences. ${ }^{4}$ The experience of being inside its noise walks the line between pain and exultant delight in its din. ${ }^{5}$ Loudness/volume alone isn't the only politicized parameter, though I note that one of my colleagues, an art music composer, has told me with regret that he can't attend the taiko class recitals because they kick his tinnitus into high gear. The inability to block out the sound of taiko-to silence it-can prompt extreme responses. Many years ago on my campus, in the middle of an end-of-quarter outdoor taiko class recital, a faculty member burst out of her nearby classroom, rushed over to Rev. Tom Kurai, who was leading the group, and literally shouted at him that we had to stop playing because she couldn't hear herself lecture. She lost it, you could say, and I was struck by how the noise shook her loose from any polite or reasoned response. Her perception of our playing as noise was both a matter of decibels and, I'm certain, an instinctively classed and racialized response. If Rev. Tom had been wearing a tuxedo, she probably would not have so easily claimed the right to shout at him while he was in the middle of leading a performance.

\section{ANALYZING “ARANAMI”}

Taiko activates relationships between order and disorder, and it forces a consideration of the organized structures of rhythm versus chaos. I will explore these issues by considering one "piece," though I intend to immediately complicate the very notion of the "piece" or "work" in several ways. Rev. Tom, my teacher and the leader of the taiko class recital mentioned above, created "Aranami" in 1997. Notice that I say "created" rather than "wrote": the idea of "writing" a piece of music is inextricably bound up with Western ideas of musical composition and music notation and immediately raises all the problems that I am writing against. It is generally assumed in the Western art music tradition that music is notated, that that notation is prescriptive (i.e., it tells performers what to do), that it was put down by an individual creator known as a composer, and that the notated object is more authoritative than any single performance. When Rev. Tom created the piece that he named "Aranami," he was the director of Kishin Daiko, a community-based taiko group in Southern California. One could say that he created "Aranami" "for" 
them, but as time went on he parted ways with Kishin and taught other groups, so "Aranami" was learned and played by a number of taiko ensembles, most recently Satori Daiko, to which I belonged. ${ }^{6}$ The piece was thus disseminated by Rev. Tom, and according to the etiquette of the taiko world, each group plays only pieces that its members created together, that their teacher created, that they received directly from another teacher, or that are explicitly known as open source. ${ }^{7}$ Anything else is a bit unseemly. In fact, it would be in extremely bad taste to "lift" a piece from another group by learning it from a recording without their permission. One could say that "Aranami" exists only in relation to Rev. Tom: no taiko player would play it without acknowledging that it came from Rev. Tom. (To listen to "Aranami," go to http://wonglouderandfaster.com.)

Was Rev. Tom the "composer" of "Aranami"? The simplest answer is yes, but the conceptual field defining a composer is historically, culturally, and ideologically complex. The Western art music tradition understands composers as individuals (as opposed to groups), who create pieces of music full blown, out of their imaginations, each of which is idiosyncratic and unique. "Aranami" is and isn't utterly unique. Rev. Tom drew from a vocabulary of formulaic rhythmic motives to create it (see Lord 1960), and he employed one of four standard ji, or taiko "base lines", as they are called in English, to underlie it. That is, the small, highpitched drum known as shime-daiko plays teke-teke-teke-teke (continuous eighth notes) throughout. The patterns that make up the piece are found in many other works for taiko, in many other groups: don don don don, doko-doko-doko-doko, su-don su-don don, and so on. Rev. Tom's compositional gesture lay in ordering these motives in a certain way, dividing them across different taiko in particular ways, and situating them in his students- "composing" with the expectation that these sounds would (at least initially) be played by the musicians closest to him. It is clear that he was proud of how widespread "Aranami" became, because this is metonymic of his impact as a teacher.

Rev. Tom regarded himself as the composer of "Aranami": he was quite aware of the Western art music complex defining pieces and composers, and he listed himself in concert programs as its composer, often including the year 1997 as its composition date. He gave the work a name-a title-to indicate that it had its own identity as distinct from other pieces for taiko. He always translated "Aranami" as "turbulent waves." By giving it a Japanese name, he located the work as Japanese American / Japanese. Sometimes he described "Aranami" as part of a "trilogy" with "Ame no Mori" (Forest of rain) and "Arashi" (Storm), because although they were not written to constitute a larger unit or group, they all have names that refer to water. Rev. Tom named many of his pieces after nature, in Japanese, and thus located himself within a traditional Japanese aesthetics of nature ... which suggests that certain signs and symbols are coded across the Japanese American-Japanese divide and acquire power and significance in each culture via the logics of heritage and orientalism. 
One could analyze "Aranami" using the tools of traditional Western art music theory, which would probably mean focusing entirely on rhythm and would also probably leave many traditional theorists at a loss, because the rhythms in themselves are not particularly "complex." A structural or formal analysis would have the same problems, as "Aranami" is quickly and easily described as having ten phrases or motives that are repeated four times, and then the piece is over. "Aranami" is a short work, as are most of Rev. Tom's compositions. Like many if not most North American kumi-daiko pieces, it is solidly in duple meter. Music theorists often treat percussion pieces as if they are entirely "about" rhythm, but one could also analyze their pitch and dynamics, which in taiko are related to the size of the drum. In "Aranami," Rev. Tom depicted crashing waves programmatically in at least two ways, through rhythm but especially through dynamics and pitch. Two phrases feature different-sized drums in a call-and-response pattern: the chudaiko play one line alone, and the lower-pitched odaiko answer with another. Also, the crescendos in some of the phrases near the end of the piece create huge, swelling waves.

Taiko players often learn pieces not only by playing them but also by "speaking" them - that is, by learning mnemonic syllables called kuchi shōga (kuchi, "mouth"; shogga, "song"), discussed in the introduction. (See figure 2, Rev. Tom Kurai's mnemonic notation for "Aranami," at http://wonglouderandfaster.com.) These syllables address only rhythm, and somewhat inexactly at that. Although these mnemonics are written down and then regarded as notation by taiko players, it would be difficult if not impossible to learn a piece from such notation: it is always necessary to hear the piece, whether played or spoken, to learn it. When taiko players "speak" through such mnemonic patterns as part of their learning or review process, they add a number of elements not present in the syllables themselves: they often move their hands as if they were holding drumsticks (bachi), to associate right-hand and left-hand strokes with particular syllables, and they "speak" dynamics not only through the volume of their voices but usually through relative pitch as well. A crescendo is mnemonically spoken by starting soft and low and ending loud and high. I would venture to say that this is how taiko players hear such lines when they play them on a drum.

These mnemonics are standard for taiko players. Many groups learn pieces orally, by rote. West Coast community groups use Western staff notation only rarely; when pieces are written down, mnemonics are most common, though a range of written techniques are used (e.g., some groups put the syllables in boxes, with each box representing one four-beat measure). Don means a quarter note at medium volume; $D O N$ is a loud quarter note; doko is two loud eighth notes, usually right hand followed by left hand; tsuku is two soft eighth notes, usually right hand followed by left hand; teke is two eighth notes on the small highpitched drum (shime-daiko); and so on. The relationships between purely "musical" parameters of this sort are only part (and perhaps the least) of the ways that 
taiko players experience and understand the works that they play. There are other ways to understand the "work" of taiko, and I mean quite deliberately to play with the idea of the "work" as an isolatable musical object and the corporeal, sensual, spiritual, and political labor that goes into creating the complex of understandings called taiko. Another way of addressing taiko methodologically is through the body, which opens up a host of issues. Rather than think of music as a sound object, I want to move toward a conception of music as body: the movement of music through bodies over time, and between bodies (both within and across time), the placement of music within particular bodies and its generation by particular bodies, the linkages created between bodies through sound, and the metaphorical leap from the corporeal, material body to the body politic and the body of the community. Resituating the music object onto/into bodies has radical implications and would work for any "piece" or tradition of music; this methodology moves the discussion away from an isolated thing, which requires much focused effort to identify its shape and its boundaries, and instead toward the connective traces of processes and activities across time and space. It offers both a material and a metaphorical means for regarding the work of music-that is, the things that music does.

For taiko, the pleasure of such an analysis is doubled because this tradition is explicitly (emically) grounded in a social, philosophical, and political aesthetic of the body. Taiko is intensely physical, and it represents a corporeal aesthetic system that is both Buddhist in origin and decidedly contemporary in its realization. The kind of kumi-daiko I learned from Rev. Tom is explicitly based in Buddhist concepts linking the mind, the body, and the spirit via the principle of ki, energy. Ki is the vital energy that can be realized physically but is in fact mental and spiritual as well; it blurs and even collapses distinctions between the physical, the spiritual, and the mental. ${ }^{9}$ The pragmatics of how ki is used and actualized in taiko comes from the Japanese martial arts, to which the taiko master Seiichi Tanaka (the founder and director of San Francisco Taiko Dojo) explicitly connected taiko by calling his school a dojo and drawing on such martial arts principles as ki and kata. His theories and approach are consistently activated by North American taiko practitioners to theorize the complex of mind/body/spirit that is viewed as central to taiko (Varian 2013, 81-95). The body is thus always more than the body: it is understood as a corporeal realization of vital principles that exist beyond the body, but without demoting the body to secondary importance. The primacy of kata, "stance," in taiko and the martial arts bespeaks this. Taiko practitioners give much attention to the body. At the very least, warm-up exercises precede all rehearsals, and the Japanese groups Ondekoza and Kodo are (in)famous for their extreme physical regimens, focused on long-distance running (Ondekoza members participated in the Boston Marathon before a full-length concert; Kodo apprentices are expected to run up to ten miles every morning before rehearsal). Preparing the body in these ways prepares the mind and spirit for the "work" of taiko. Bodily experience is something that taiko players like to talk about and to theorize. Blisters and aching muscles are honorable parts of the taiko experience, 
but they speak most deeply to the centrality of the corporeal/spiritual conjuncture in taiko (see chapter 6). Some groups bring beginning students into the tradition through physical exercises, introducing them to the drums and "the music" only after weeks or even months of bodily training. In her groundbreaking monograph on Japanese dance (nihon buyo), Tomie Hahn $(2007,67)$ emphasizes the organic links between ki, kata, and hara, the abdomen as the physical location for ki in the human body and the bodily site from which motion begins: "Japanese aesthetics and concepts of the body are integrally linked." The hara exemplifies this: it is located in a physical place on the body (just below the belly button), and all bodily stances (kata) emanate from it; although your kata may be technically correct, you cannot move with ki unless that movement begins in the hara. A drum stroke, a karate strike, and a dance step are all manifestations of ki that begins in the hara. The ki/hara/kata complex offers an approach to performance that is simultaneously physical, spiritual, and mental.

"Aranami" is a bodily experience, both individual and shared. Rev. Tom tended toward minimal choreography (unlike some groups, who put extensive effort into choreography for its own sake), with few unnecessary movements. In "Aranami," as in many of his other works, the individual players stay put throughout, standing solidly in front of each drum (whether shime-daiko, chudaiko, or odaiko). Playing "Aranami" makes you feel strong, and this is all in the upper body, since the lower body doesn't move at all. Starting out with strong, steady, repeated strikes (don don don don) rather than a more complex or involved set of rhythmic motives is strong; doubling the density of those repeated strikes (doko doko doko doko) - and thus doubling the effort-is strong. The repeated gesture of accented downbeats with the right hand is strong: the sensation of flicking out those accents-of raising the right arm a little more and then flinging the extra ki out along the arm, from shoulder to elbow, then through the forearm, snapped through the wrist and out the length of the bachi-is strong. Moreover, these repeated accents and the physical gesture creating them, just described, are a physical representation of a wave. Certainly, this happens too quickly to register visually for a viewer, nor do taiko players explicitly think or talk about the motion this way, but if you slowed down video footage of the right arm as it pushed out these strong accented downbeats, it would register as a retreating and advancing wave.

Another key gesture in "Aranami" is the four-count "rest" in the middle. Sonically, nothing happens in that rest except that the lone shime-daiko continues to play the base line (though one of our shime players is fond of jazzing up this measure). Again, a sound-focused analysis would miss the point of this "rest," which is anything but a rest. It is filled with the slow, considered movement of raising the right arm from the drumhead to full extension above the head. At its best and most ki-filled realization, raising the arm doesn't begin straight from the drumhead but is rather preceded by a quick pull back that allows the player to bring the bachi up from below in a scooping and arcing motion, literally pushing the bachi up, leading with its tip in a movement that actually generates a tremendous 
amount of ki as the arm goes up to full extension. You can feel your body fill up with additional ki if you do this. You find yourself instinctively inhaling through the entire motion, the entire measure, filling yourself up with air, expanding the chest. The next phrase-SU-don, SU-don don-is explosive for two reasons. First, its expenditure of ki matches and exceeds the generation of ki in the "silent" measure preceding it. Second, the half-beat "rest" at the beginning of the phrase-the first $s u$-generates yet more ki, but in a slightly different way from the measure preceding it. Taiko players don't experience that half beat as empty: it is marked with the mnemonic $s u$, and this may be literally shouted or may be sounded in the head, silently (though at this point there is no distinction between sound heard and sound silently felt). Furthermore, the movements most filled with ki always have a pronounced beginning. That is, the most ki-filled movements are propelled into motion via a slight drawing back or pulling up in a quick, small gesture that makes all the difference. In other words, the arm doesn't just start moving: an extra small movement gets the big movement into motion. It is like a kick start, and it too generates ki. Rev. Tom explained and demonstrated this in his classes; again, this is part of the theory of taiko and ki. The half-beat "rest" at the beginning of this measure should be filled with that kick start-that is, the arm should already be fully extended above the head as it arrives at the end of its arc from below, but in that split second of $s u$, you raise your arm through the shoulder a few inches higher still. Indeed, that small additional lift starts all the way down in your feetyou may even lift up from your toes-and at this point it becomes evident that the lower body has not been immobile and uninvolved through all of this. Rather, that arc from below may be visually defined by the right arm, but it is galvanized by a slight pivoting rise through the legs and torso. The kick start involves the entire body, really: the reach upward is created from below, starting down at the toes and rising through the legs to torso to shoulder to arm to bachi. Rise up into the kick start and bring the right arm down on don at the same time as you explosively exhale ... and as you simultaneously raise the left arm in a scissors motion to put it into position for the next movement. If you are doing this correctly, everything comes from the hara: certainly, your abdominal muscles should be tight and engaged, but your ki should burst out from your solar plexus and down your legs and out your arms and into your bachi and through your bachi into the drum.

This is a complex set of kinesthetic relationships, you might say, to create such a small moment. Yet it is metonymic of a bodily theory of taiko. It has taken me a long paragraph to unpack the physical movements in one measure of "Aranami," so this is a microanalysis at best, but it also addresses a number of assumptions. How should we think about the relationship between sound and movement? It is a problem of vocabulary and more: shall I say that the movement is "behind" the sounds, or that the movement "drives" the sounds? Neither metaphor really works. "Fronting" and "backing" aren't accurate descriptions of the sound-body relationship-the theory of ki makes that clear. Nor is sound simply a consequence 
of something more primary-movement isn't in the driver's seat of the sound machine. Rather, the circular, synergistic set of relationships between body, ki, and sound is made visible and audible when a microanalysis of this sort is offered.

The boundaries of "the work" in taiko are not always easily defined. My university campus has a club called Senryu Taiko that is run and organized by students; like many collegiate taiko groups in North America, they mostly create their own repertoire, but they learned "Aranami" from Rev. Tom around 1998, when they were still establishing themselves. When I saw them perform it in 2004, I didn't recognize it for a moment: the rhythmic patterns were "the same" as those I know as "Aranami," but the students had completely transformed the feeling of the work by creating their own choreography for it. Senryu Taiko used two kata (first diagonal, then facing the chudaiko) and utilized the space around their chudaiko in strikingly different ways than Satori Daiko, by shifting stances and deploying a broader range of strokes, such as large sweeping strokes that crossed in front of the body..$^{10}$ The overall effect was extremely graceful and physically lyrical, unlike the powerfully grounded and stationary effect of Rev. Tom's minimal choreography. The students always credit the "piece" as Rev. Tom's (e.g., on concert programs), but they perform it in ways that he never would have, that offer their own distinctive interpretation.

"The work" is thus something flexible and potentially open to rearrangement and rechoreographing, though in this case it retains its original attribution to Rev. Tom. This comparatively open-ended approach to authorship attaches "the work" to an originating individual, though it assumes a slightly different shape and character in its bodily realization by another group. Such difference isn't thought of as mere ornamental detail laid over "the work" itself. I literally didn't recognize "the work" as "Aranami" for a long moment when I watched Senryu Taiko's version of it, despite the fact that "Aranami" is part of me, heart and soul, since I have played it so many times over the years. I was disoriented for that long moment, suspended in a jarring sense of knowing but not knowing. It sounded familiar, but I didn't know what it was because its bodily realization was so different.

But this "analysis" needs to go further. Kumi-daiko is literally a group experience-few of us ever play alone, except to practice-and that needs to be part of any analysis. This is a tradition of massed drums, with no emic theory of how many are too few or too many. I played "Aranami" with approximately one hundred other taiko players in 1999 for the opening of the Pavilion of the Japanese American National Museum in Los Angeles. ${ }^{11}$ The experience of the sound and the experience of playing are meant to be multiple: many sounds, many performers. Satori Daiko has eighteen members, and we are used to a certain density of sound. As in many amateur taiko groups, some but not all of us have "training" in music, which means that we don't all play with a metronomic sense of exactness or subdivision, and we don't play as a large group with an expectation of rhythmic precision-whatever that might mean. Some of our members have extensive 
Western art music training, and the group's inexactness of attack and inability to control tempos with any certainty are sources of frustration for them. In this community of performers a diversity of ability is a given, though not all participants accept this with equanimity. Another way of putting it would be to say that the amateur taiko scene does not discourage participation based on a lack of musical training. It is assumed that playing makes you into a musician-not that you must be a musician in order to play. Musical chops are recognized and admired, but they are not the only criterion for being a "good" musician. Rev. Tom selected the members of Satori Daiko from his many classes, and he said more than once that solid playing ability in itself wasn't the only or even the main thing that he looked for: he chose students who had a good "attitude" as much as anything else, and that attitude is the thing often referred to as "the taiko spirit," a set of values that include a lack of ego or arrogance, the ability to work well with others, the choice to put the group before your own concerns, the will and desire to learn, and the motivation to work hard. When we rehearse, we go over the matters that contribute to good "ensemble" playing in other kinds of music (timing, choreography, dynamics, and so on), but we also attend to spirit. We are used to hearing quite a bit of flamming: we don't all come down on downbeats together in any absolute sense. We have limits to how much flamming we will tolerate for ourselves, but these limits are not the same as those for studio musicians. The relationship between playing with spirit and playing with metronomic exactitude has a wider envelope for us than for some other traditions. ${ }^{12}$

Playing with a group of other people has deep bodily implications. We are trained to look around us, at one another and at the audience; there is no notation in which to bury our heads or eyes. You become used to the sensation of hearing and feeling sound all around you. Taiko is invasive: a deaf musician could easily become an accomplished taiko player through the bodily reception of sound vibrations and visual cues. The shime or the kane (a small struck gong) cuts through the mass of other sounds, so "listening" in taiko is both selective and involuntary: you are subject to all the sounds around you but learn to focus on some over others.

But isn't a lot of music making like that? What do performers in any tradition hear, and how are they brought or socialized into certain kinds of listening? The multiplicity of sounds (notice that I am avoiding words like inexactness and imprecision) that is so much a part of amateur taiko groups is hard to talk about because taiko players are subject to the aesthetics of Western art music, which neither values nor encourages messy playing. But the theory versus the practice of taiko is an essential distinction, and the noise of messy, imprecise, unprofessionalized playing is quintessentially part of the political aesthetics of taiko. In flamming, I hear something besides an inability to subdivide: I hear the activation of the body politic.

Taiko has been central to Japanese American and Asian American identity work since the 1970s. Taiko posits strength, discipline, organization, group consciousness-the very things that define the Asian American Movement as a 
political presence. Not coincidentally, Japanese/Asian Americans turned to taiko during the decade when universities were creating ethnic studies programs and when the Japanese American reparations movement was defined, articulated, and operationalized (E. Yamamoto 2001). Taiko was part of an assertive new Asian American sensibility, and it came to represent not only Sansei confidence but also the political consciousness that being Japanese American is also being Asian American and that the incarceration affected all Asian Americans. The pan-ethnic gesture of "Asian American" is a coalitional grouping, not an erasure of history or difference. The cover of William Wei's important The Asian American Movement (1993), for example, features a photograph of a taiko player at a demonstration commemorating the death of Vincent Chin and protesting anti-Asian violence. ${ }^{13}$ Taiko became a metaphorical and an actual manifestation of the Japanese/Asian American body politic, though the extent to which this is acknowledged or deliberately activated varies. Part of the power of the taiko body politic, I think, is the dynamic difference between Japanese American and Asian American as separate but interconstitutive and even overlapping identities. This is central to my own interest in taiko and was manifested in some of the sites where we performed. In April 2003, for instance, Satori Daiko played "Aranami" at the annual pilgrimage to the site of one of the ten Japanese American incarceration camps: Manzanar, in the high desert of central California. All these camps were in remote areas, and few have any remaining structures; most are now barren expanses of rock, grass, sand, and tumbleweed punctuated by the foundations of the barracks that housed more than 120,000 Japanese Americans from 1942 to 1945. Since the 1970s-that key period when Japanese Americans and Asian Americans got politically organized-former internees have arranged annual pilgrimages to these sites, keeping memory alive and linking past and present civil liberties issues. The pilgrimages always feature music, speeches, religious services at the camp cemeteries, testimony from the now-elderly surviving internees, and more. They are a compelling example of consciously created ritual. When Satori Daiko participated, we spent a long morning in the sun and desert wind surrounded by others determined to remember-former internees, young Asian American activists, local schoolchildren-listening to music and speeches and participating in an interdenominational religious service. We played "Aranami" with the snow-topped Sierra Nevada behind us, the hot wind in our faces, and the stirring, sobering presence of Manzanar's ruins around us. (See video 13, Satori Daiko playing "Aranami" at the

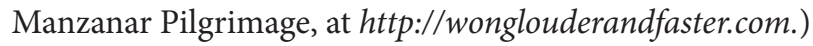

What did "Aranami" mean in that context? One could riff on the programmatic meaning of turbulent waves and the metaphoric connection to advocacy and resistance, but these weren't Rev. Tom's original intent, nor were they brought up at the time-the work is simply part of our core repertoire, you could say, and its nonspecific message of strength and power fit the bill. At another level, the sheer presence and sound of a taiko group-any taiko group - was the point, for all the metonymic reasons I have noted. At yet another level, we were there because Rev. Tom 
had worked with the founders of the Manzanar Committee in the 1970s, when he was drawn into the Asian American Movement and the Japanese American reparations movement, so our presence in 2003 was an extension of his personal history and his coming into political consciousness as a young Japanese American. Satori Daiko was one way that Rev. Tom participated in a body politic, and therefore we did too. "Aranami" became part of a web of associations: First World / Third World patterns of labor migration, the racialization of bodily economies, and the surveillance of these economies. This aggregative process is the mechanism behind political process: How do individuals draw together into formations? How does an idea become shared? How does a movement become political action? How is the body politic activated?

I now draw together the three parts of my argument into a methodology for how music might be addressed. Musical sound is a bodily product; attending to the body means taking experience seriously; experience is always individual but implicates the collective. The production of musical sound through the body politic is the thing most worth getting at, it seems to me, and a few key ethnomusicologists have focused on this challenge at both the micro and the macro levels.

I focused above on the dynamic sound phenomenon of musicians playing together in ways that draw on the sonic reality of multiple presences. Charles Keil (1994) argues that imprecision is centrally part of the excitement of live musicking: the micromoments of coming in and out of any exact or absolute conception of downbeat or pitch are what make the music dynamic, vital, powerful, moving, and simply interesting. He writes, "The power of music lies in its participatory discrepancies," and "Music, to be personally involving and socially valuable, must be 'out of time' and 'out of tune"' (96). By focusing on the moments when things don't line up exactly, he identifies the "discrepancies" that make performance alive and "participatory"; he prioritizes liveness, couching it in terms of a cultural "ecology" of life, identity, and performance that is both compelling and oddly romantic (97). Keil argues for peak experiences achieved through live performance with others, whether while dancing a polka or listening to the blues, as moments when we are "swept up," full of "euphoric feelings," and immersed in a "deeper and more satisfying knowledge of who we are" (98).

The ethnomusicologist Steven Feld's (1982) expansive work on a Kaluli community in Papua New Guinea also situates sonic multiplicity as a principle. In conversation with Keil $(1994,114)$, Feld posited the "lift-up-over-sounding" sonic aesthetic of the Kaluli as a world view or, as he put it, a "spatial-acoustic metaphor" that becomes more broadly and deeply a model for perceiving the world and relationships between everything in that world. The Kaluli most value musical sound and conversational speech that is dense and overlapping, drawn from their perception of the sonic and visual space of the Papua New Guinea rain forest.

In short, these two ethnomusicologists-who not coincidentally have worked together closely over the years-have both focused on how sound relationships 
map out the imbrication of aesthetics with everything else in a culture, from social ecology to environmental ecology and beyond. Both suggest that sound relationships matter, though always in locally specific ways. Both focus on how the sounds don't "line up," as it were, and they find important and epistemologically essential meanings in those overlappings and discrepancies. This is not to say that all musics everywhere contain their most profound meaning in mismatch and misalignment ${ }^{14}$ but rather that the very terms of such values probably tell us-and the people making them-something important. This is more than a reiteration of homology models for music and culture. ${ }^{15}$ Musical sounds have a synergistic relationship with the body politic and with the supercultural and subcultural interactions posited by Mark Slobin (1993). Sound and movement are realizations of the body's work as well as sites where the body is (re)formulated. The body in performance does a lot at once: it moves in obedience to supercultural imperatives, it recapitulates the terms of that obedience, it formulates the means for questioning and refusing those terms, and so on, and all this happens simultaneously. For instance, the ethnomusicologist Veit Erlmann $(1996,25)$ compares the work of the body in the late capitalist First World to its placement in the laboring Third World and argues that these locations outline different ways to understand "the work in the work of art." Which is emphasized, and which is most enabled: the agency of the body's work, or its control?

As the musicologist Christopher Small $(1998,213)$ puts it, any musical performance articulates a "whole set of ideal relationships" between sounds and between people. Small took a long look at the late twentieth-century phenomenon of Western art music as a cultural construction, and he didn't like what he saw. He reflected on the practices defining the performance and reception of symphony concerts and reluctantly concluded that they were "too hierarchical, too distant, and too one-dimensional for [his] taste." Arguing that the music we choose to make and listen to tells us what kind of world we want to live in, he came to the painful conclusion that the repertories which had been "a source of pleasure and satisfaction since [his] earliest days" no longer worked for him-that they went "counter to the way [he] believe[d] human relationships should be" (220). He insisted that the question for anyone must then be "Who am I that I should go on wanting to play and hear the works in this repertory?" As a young musician, I went through the same process of immersion in and identity formation through Western art music, and later, as an ethnomusicologist, I not only reached the same conclusion as Small but went in search of musics that constructed different versions of social reality and different models for ideal human relationships. As an Asian American ethnomusicologist, I think taiko provides a compelling template for a social, cultural, and musical reality that unambiguously emphasizes relational experience.

I realize that I still haven't focused on sound. One could say that I have written around it, circling around the thing itself, addressing the bodies producing the sounds more than the sounds themselves. Working through "Aranami" has shown 
me this: my own immersive experiences of the piece generated a pressing desire to understand how and why it is so thrilling to make its sounds and hear them alongside other people, both taiko players and audience members. Clearly, I am both unable and unwilling to talk about the sounds "themselves" as isolatable or meaningful. I have followed Small's lead in finding that for taiko practitioners, performance is more meaningful than composition, the experience of performance (and not the "music itself") is foregrounded, and the embodiment/enactment of sound creates affective, choreographic structures of meaning and effect that are just the opposite of the objectified structures at the heart of traditional music analysis.

In sum, these are the matters that can be pursued through "analysis": the primary values and the social vision driving the experience of music, whether hearing or performing. That experience may or may not be euphoric or one of flow-it may manifest in very different terms than those I described for taiko-but it will certainly hinge on the shift in sensibility from the individual to the collective and back again. I close with the sense that "Aranami" is and isn't something that holds still or something that allows analysis. It suggests that vestiges of the body and the work of performance may be found in a piece of music, but such a piece might better be regarded as a stopping-off point, a room with many doors. Attending to the sonic means redefining the act of listening.

\section{LOOKING \#1}

Look at the group of photos taken by one of my taiko friends (video 1, montage of Gary St. Germain's photos, at http://wonglouderandfaster.com). Gary St. Germain and I-and about fifteen other amateur musicians, mostly Japanese Americanwere in Satori Daiko together through most of the 20oos. Now in late middle age, Gary is hapa haole (in his case half Japanese and half French Canadian). He is a public school music teacher, a rock and roll drummer, and a very serious amateur photographer. He has probably taken thousands of photos of Satori Daiko over the years. I told him I wanted to feature some of his photos in this book, and I asked him to send me around ten of his favorites. These are the ones he sent.

I looked at them and realized he hadn't sent any photos of our group, so I asked him if he could send some favorite photos of Satori Daiko in action, and he sent the ones in video 2, montage of Gary St. Germain's photos of Satori Daiko, at http://wonglouderandfaster.com.

These are all striking and even accomplished photos. I'm not sure they offer the story I want to tell about taiko, but I see a specific aesthetic at work in these images. I have been perplexed for some time about how to take critically effective photos of North American taiko, especially of my group. Documenting events in which you are actively involved is a practical and a political challenge. Do I step out of the action so I can capture it? Do I help serve food, carry equipment, talk with friends, or do I step away so I can document other people doing those things? Do I put my own sociality on standby or do I participate? 
But I've been even more challenged by deeper matters. One can't see taiko without a lot of historical interference at work. I can't see taiko without reenacting and revitalizing other ways of seeing, including the colonial gaze and its contemporary cousin, the multicultural gaze. It is impossible to do visual documentation of any kind (still photography, video, etc.) without reenacting colonial and touristic traditions of looking. I can't see taiko. I am blind. I am frustrated because I am at the mercy of inculcated ways of seeing that have colonized my ability to look. Throughout this chapter, I mark this valence of seeing by italicizing it. This is the act of looking that I want but can't achieve. This is the ability to look at my friends in a way that refutes everything framing us: it is an intervention of the most basic kind, a willful act of performative perception that is at once unattainable and necessary. I want to see taiko, and my friends playing taiko, in a way that reactivates certain histories without being defined by them. I want to see the performance of difference through taiko in ways that quickly acknowledge the problems (orientalism, etc.) and then force an engagement with other narratives-other stories about performance and alterity.

I want an ethnomusicology that moves restlessly between media and assumes a translative shiftiness. This ethnomusicology takes performance more seriously than we have allowed. Ethnomusicologists always come back to the text as the ultimate medium of representation. We are excellent wordsmiths; we are adept at talking around the thing itself; we know how to speak "for" it; and we even know how to stop performance so that it can't move around, so we can control the moment and shape that we want to take in hand. We pay little attention to motion, whether through time or space.

I don't want to rehearse and retread and re-create the politics of display here. Hundreds of books and articles have been written on these matters, mostly since the 1980s, addressing the long reach of colonial surveillance and its contemporary presence in images published by National Geographic, Kodak, and Benetton. "Color" is a primary trope in these matters. Color is a literal value, in the sense that the more colors are in a picture, or the brighter they are, the better. Brighter and more colorful people enact a (social) aesthetic that positions variety as visually pleasing and geopolitically comforting. Brightness and cheerfulness are coterminous: clean, smiling, vivid people of color are fun to photograph, and their smiles mean that they are happy to be photographed and happy to be taken home in your camera. They are available, ownable, transportable, accessible. All this is old news.

\section{PICTURES THAT MOVE}

The image must be compelled to speak. How does the photograph-this still, silent object-become the thing itself? How can we choreograph it back into movement, let alone into sound? We need to dance with it and engage with it as if it were a partner in a duet. 
Ethnomusicologists consistently use photographs in severely limited ways, often to say little more than "I was there" or "Here's an instrument. It has twentytwo strings." The work of Charles and Angeliki Keil $(1992,2002)$ stands out because they combine music and photography, often working with the photographer Dick Blau. I love Blau's photos of American polka dancers and Roma musicians, and the Keils' grounded words about them. Text and image interact; neither is primary; the frisson between the two is unexpected and stays with you beyond the page.

One of the few standard ethnomusicological monographs that pulls this off is Steven Feld's Sound and Sentiment (1982). Feld has experimented with audiovisual media in any number of ways, often pushing the boundaries of accepted practice and wisdom. He too is weighted down by heavy genealogies of "documentation," but he often turns this around and makes it work for him. Near the end of his book, he inserts two color plates that do important critical work. First, he offers a standard photo that gives the viewer the expected full, unobstructed view of a performer, allowing us to take in and own every detail of the man's costume. As Feld puts it,

The first image has a form that is frequent and conventional in ethnographies. We assume that it represents someone doing what he normally does. With no further information about who is represented here or what he is doing, it is easy to take refuge in the structure of the image-conventional Western portraiture framed in a medium shot-and to assume that this framing is a significant way to depict a Papua New Guinean dressed in a ceremonial costume holding a drum. Further attention can then be directed to the costume itself, the body painting, the red and white feathers, and the palm leaf streamers.

It is clear, however, that these things are not the meaning of the image, nor is the simple meta-message "the photographer was in Papua New Guinea and saw this costuming." The image could have been made at any number of places, and we have no other internal information to indicate the photographer participated in some event for which the costume was made and used. (233-34)

Then you turn the page and see something extraordinarily different. Feld writes:

The second image is clearly not an attempt at iconic depiction, and only the deliberateness of its presentation here might lead one to decide that it is intentional and not a representation of incompetence....

[It] was very premeditated. Two days before the event at which it was made, I spent the day talking with Jubi and asked him to describe what was going to happen. I wanted to get a sense of the anticipatory feelings that accompany the planning and staging of ceremonies. At one point he remarked: "In the middle of the night, while the dancers continue, dancing and dancing ... you get tired and lie down ... and then, all of a sudden, something startles you, a sound, or something ... you open your eyes and look at the dancer . . it is a man in the form of a bird." I was taken by this description of that hypnotic, tired, dreamy sensation promoted by a long evening of song, as well as the implication that one is emotionally prepared to experience the ceremony in this way. 
Jubi's remark was the basis for the second photograph; I decided to use a metaphoric convention from my own culture's expressive tradition in photography to make a synthetic and analytic statement about a Kaluli metaphor. $(234,235-36)$

Turning the page from the first image brings the viewer into another world: the dancer is in motion, the photo is blurred, and the longhouse is dark. What might have been discarded as a bad photo is instead one of the most stirring moments in the book: the man becomes a bird before our eyes, dancing in the deep night. Feld explains that this was the only time he stepped away from his "imaging behaviors as an ethnographer" (1982, 236). He calls this attempt "co-aesthetic witnessing" (236) and describes the photo as an encore to the rest of the book, though it also forecasts his subsequent experiments with soundscape recordings and more. It is an effort to see differently and to participate in an aesthetic by doing more than just looking. The photo moves. The viewer (you or I) looks at the photo and sees not only Feld's shift in perspective but an invitation to see with.

Similarly, Louise Meintjes $(2004,176)$ uses a photograph to convey the power of the kick in Zulu ngoma. In this extraordinary photo by T. J. Lemon, the dancer Bafana Mdlalose is seen head on. His body fills the frame; a woman behind him is blurrily out of focus, so our eyes are drawn to nothing but him. His posture is impossible: at first you can't make out how the parts of his body can be where they are. His right foot is high above his head; the sole of his shoe dominates the top left corner of the photo. He is grimacing, and his stare is directed somewhere above the viewer's head: Lemon caught him in the exact moment of kicking his foot into the air, so his arms are down and his body is powerfully contracted. He is shouting; we can see his teeth and the lines in his forehead. We can't help but admire the musculature of his shoulder, his left arm, his left thigh, and the startling back of his right calf and hamstring. His posture is powerfully unnatural. The focused energy of the move clearly comes from the core of his body, but the photographer has deliberately left this dark, shadowed-the energy comes from a place we can't see. Mdlalose's entire body makes visible the physical effort of the kick-this key choreography of defiance. Meintjes describes this moment:

Of the hardest hit they say in Zulu "inesigqi!" (It has power!). The hardest hit has power. The voiced palatal 'click' - $g q i$ is an aural icon of the thud of the foot hitting the ground after a high frontal kick in the Zulu men's dance styles called ngoma. After a preparatory sequence, the dancer's right knee bends, his back arches, his head tilts back. He extends his right arm over his head as his left leg stretches back to prepare for the pick-up to the beat. The forward thrust of his left arm balances his taut and arching body. Then, as if a spring suddenly triggered, he kicks his left leg into the sky, curls his torso and shoots his right arm forward to balance his one-legged stance. His skyward foot thunders down onto the ground on the beat, gqi! Dust flies. He throws away the movement with his hands, in the recoil of his torso, with a flick of his head, and he saunters off. (174) 
The relationship between the photo and Meintjes's vivid paragraph isn't clear. Is she describing this dancer, or is her description generic and the photograph an apt but nonspecific example of such a "high frontal kick"? Her purpose is to reintegrate sound, the body, and politics, and her justly famous article offers a compelling model. She unpacks how ngoma generates "that sense of total dense consolidation" of collective song, dance, and purpose (180). She articulates "the absolutely dialogic relation between the kinetic body and the sound as two expressive elements that collectively compose the form" of ngoma (184), and the similarities with taiko are strong.

Coaesthetic witnessing is a critical move that means the ethnographer has made an ontological commitment to try to see, which probably means feeling, knowing, listening, carrying things, and more. I aim to leave the documentary impulse behind and move instead to enact core values in every frozen moment. This is a shift in intent and position; this is a performative commitment.

\section{HOW I DON'T WANT TO LOOK AT TAIKO}

capture

take

shoot

snap

freeze

Photographs of performance are so predictable. It's as if photographers think they've been granted automatic access to people's souls and, worse, have already decided what (they think) they know about those souls before taking the picture. There are an impressive number of clichéd ways to look at taiko and to capture it. Most performance traditions have clichéd photographic expectations. The jazz sax player, always a cisgender man, is always captured blowing out a high note with his eyes squeezed shut. This is supposed to tell us that he is full of emotion, that he is putting "everything" into it, that body and soul are one and the same (a trope mapped onto any music with African American roots), that he is so deeply into the music that everything else has vanished, and so on. Classical pianists are photographed hunched intensely over the keys or in transport, with their head thrown back and eyes closed; they are never, ever, ever photographed smiling while they play.

Stereotyped ways to depict taiko players are clichés because they enact and maintain certain narratives about the tradition. The odaiko is generally the largest kind of drum in a taiko ensemble and is deeply connected to specific ideas about masculinity, strength, and authority. I write about these matters at great length in chapter 5 , but here it suffices to say that men are far more likely to play 
virtuosic odaiko solos than women. Gendered ability is never "natural," though it certainly takes considerable upper-body strength to play above shoulder level. No rules decree that men should play the odaiko more than women; rather, a series of historically specific practices have hardened the gender associations between men and the odaiko, particularly the spectacular solos played on odaiko by members of the Japanese taiko groups Ondekoza and Kodo. As a result, playing lengthy virtuosic solos on this instrument is at once a sign of strength, stamina, gendered authority, and cultural authenticity. Following from that, many taiko players, especially men who want to be known for their abilities as soloists or as master teachers, tend to have their photographs taken at the odaiko, often from behind. They often display quite a bit of skin as well, partly in homage to Kodo but also to show off musculature. This kind of photograph thus tells a story about mastery, discipline, and roots: this stereotypical image depicts a body grounded in the most authentic practices ... even when it's a woman doing it. When a woman is inserted into this generic taiko photograph (and she can be only an insertion, not an authentic presence), she is understood to aspire to the kind of fame and regard normally reserved for men in this tradition, especially in Japan. A few women-especially Tiffany Tamaribuchi-have effectively redirected and even disrupted this iconic image, but only by first evoking it (Ahlgren 2008). In short, this kind of photograph is endlessly restaged and reshot because it tells a story that certain people want and need. Some of those people are taiko players. Others are not, and they want to capture or consume an idea of taiko reflecting their need for particular kinds of authenticity or authority.

\section{LOOKING \#2: WHY IT'S HARD TO PHOTOGRAPH} JAPANESE AMERICANS

As Joseph Jonghyun Jeon (2012, xiii) writes, the "dark trope in American history" is that "racializing objectification erases subjectivity." Asian Americans simply aren't seen, and when we are, the refracting lens of racialized logic ensures that something else comes into focus and our subjectivity vanishes. The exuberant visuality of taiko is necessarily, inevitably, and disquietingly in permanent negotiation with this dynamic. Many of my taiko friends are Japanese Americans who have lived in Southern California for much if not all of their lives. Their families are mostly from this area, and they are rooted in an extensive Japanese American community that stretches across some four generations and the sprawling suburbs of greater Los Angeles. Two degrees of separation is the most that anyone seems to have from anyone else. This extended community is framed by the historical fact of the Japanese American incarceration. Almost everyone has relatives who were interned; one member of Satori Daiko was born in an incarceration camp. The incarceration is a mostly unspoken but defining presence. 
The incarceration camps were photographed in specific ways by specific photographers, and a small body of fine scholarship has emerged on this, particularly the work of Elena Tajima Creef. Ansel Adams's and Dorothea Lange's photographs offer contrasting approaches to looking at the incarceration, both critical but profoundly different from each other. Adams created aestheticized portraits of heroic American citizens, often in carefully composed arrangements of line and light. Lange went for messier images of drudgery and the weary work of incarceration. Both photographers assembled gripping bodies of documentation, each infused with certain political sensibilities-Adams's assertion of the "good" Japanese American citizen, Lange's thinly contained sense of outrage-but neither corpus can be described as coaesthetic witnessing. Both photographers were profoundly manipulative. Providing a political critique involved aestheticizing Japanese Americans in ways that are now part of my ability to see and to know. As Susan Sontag $(2003,76)$ wrote, "Transforming is what art does, but photography that bears witness to the calamitous and the reprehensible is much criticized if it seems 'aesthetic'; that is, too much like art." These beautiful black-and-white images of the emblematic wound to Japanese America are centrally part of what I see when I look at taiko.

Fast-forward fifty years to the present, through the civil rights era and the Japanese American fight for reparations. The problem of the incarceration has been solved and the predominant narrative in SoCal is multiculturalism and the celebration of difference. Multicultural festivals punctuate the landscape like bright smorgasbords, colorful and tasty and fun to see. Satori Daiko plays at festival after festival, in city parks, in blocked-off streets, in parking lots. My hard drive is full of the same photograph taken over and over again: we're on a stage, playing for an audience sitting in folding chairs or passing by with children in strollers and dogs on leashes, eating hot dogs or funnel cake. Everyone's having a good time. The sun is out. The same banner is behind us on stage, saying that we're in Gardena or Monterey Park or Ventura and that the festival's sponsor is Budweiser or Target or WalMart. The group waiting to come on is a Brazilian samba troupe or Chinese ribbon dancers or a local rock band. We're playing our hearts out, but it's the same photograph: We're part of a story that's being told about us. No, we're telling that story ourselves, whether or not we meant to.

I can't reconcile these images. I look at these pictures and I realize all over again that I can't see-I'm looking through someone else's eyes, like in those sci-fi stories where the protagonist has been transported into someone else's body. I don't want to be in this body. I want to be able to see in my own ways.

THREE WAYS OF LOOKING AT TAIKO

In his poem "Thirteen Ways of Looking at a Blackbird," Wallace Stevens offers this final way of looking: 
XIII

It was evening all afternoon.

It was snowing

And it was going to snow.

The blackbird sat

In the cedar-limbs.

Time is suspended. Things are happening and are anticipated. A dark, vital presence punctuates this: the blackbird has a marked stillness and is a defining reference. The blackbird is to time and snow what a photograph could be to performance. It immobilizes the ephemeral things that are so beautiful and so important, but without judgment, violence, or desire. It is a cipher, but it allows time and action to continue to move, flow, and stir us.

Let me offer three ways of deploying still photography to learn something about taiko. I want to use photography to learn about taiko, ethnomusicology, ethnography, and difference all at the same time. I want to get beyond "I was there" and "This is what the musical instrument looks like." I want photography not to be self-evident. I want it to be more than an extratextual way of saying the same thing as the text. I want it to require conversation (both speaking and listening). I want looking, feeling, and understanding to be pushed into a circle of interconstitutive effort, through the text, through a cross-media circuit of translative exchange between the writer and the reader. It's meant to be a mutual effort in the way that a good conversation is shared work and shared play. Here are the three ways of looking at taiko:

1. This is what that moment feels like.

2. This is how that moment opens up.

3. This is how these moments come together.

I'll start with \#1. If we really want photography to "capture" a moment, then we should put more thought into why some moments are worth capturing or are (in)appropriate to capture and why the temporal gesture of freezing/capturing/ slowing/objectifying the ephemeral motions of performance is something worth doing. I have already addressed the problem of aestheticizing through the act of stopping and the kinds of beautiful violence wrought by the unitary eye.

The photo in figure 3 (Taiko Center of Los Angeles members playing "Amano," 1998, at http://wonglouderandfaster.com) was taken about a year after I started playing taiko; I don't remember who took it. It's been used countless times as a PR photo for the Taiko Center of Los Angeles. It catches us in a particular moment in a piece called "Amano," short for "Amanojaku," which is associated with a taiko group based in Tokyo. It isn't literally programmatic-we're not pretending to be amanojaku, the little demons who can convince people to act on their worst desires-but it uses some rhythms from Kabuki and has a dramatic choreography, 
seen here. The central phrase stops in the middle with a one-beat rest in which the taiko players freeze with their arms in the air. This is what that moment feels like: if you do it right, you use your entire body to push your arms into the air above your head, working up from the hara, drawing on the rootedness of your thighs and feet in basic kata position. You can do this only if you allow yourself to be relaxed and flexible, if you allow your entire body to move in a quick flow of related parts. You should think of your arms, hands, and bachi as arriving at a certain point-that is, you need to envision a point of arrival, with your bachi in a slight $\mathrm{V}$ so that they stop at dynamic point where they're about ten inches apart at the tips but feel as if there's electricity crackling between them. You STOP there, for a long second: everything should arrive and STOP. This is pure $m a$, an empty dynamic space that gives meaning to everything around it. Then you pull your arms down for six eighth notes-DORO-tsuku-DORO — and then repeat the gesture, thrusting your arms UP. When you arrive at that moment with your arms in the air, you can shout Ho! if you like, to punctuate it, to fill it, to help define the exact point of arrival.

The now-forgotten photographer caught me at that moment. I didn't achieve the right combination of flexibility and arrival every single time. "Aranami" is an aerobic piece to play, and sometimes I tired toward the end as the tempo sped up and it became harder to catch the moment just so. But this photo shows me arriving at ma perfectly. By perfectly I mean that my kata looks right, but I'm really saying that you can tell I got it from the look on my face as much as from my actual form, which is literally perfect (said in all humility-this was not always the case). On the left, Janet Anwyl didn't quite get it-look, the bachi in her right hand is still cocked, so she didn't think of pushing up using the ends of her bachi like arrows. On my other side, Irene Ogata got there but is trying too hard: look at how her shoulders are hunched up-you can see how stiff she is and how she's forced the movement rather than pushing up from the core. It's in her face too: she has a kind of blank, frozen stare that shows she's all inside her head, thinking too hard rather than directing her ki outward. I can tell you all this because I've been there and done that.

This is how that moment opens up. Any moment is set within many other moments, some of them side by side, others far away in space and time. Let me turn to another photo: figure 4, Audrey Nakasone airborne, at http://wonglouderandfaster.com. This isn't a great picture, but I love it because of the series of moments it offers. This is Audrey Nakasone, formerly a member of Satori Daiko. I miss her. It all ended in fraught ways, as it sometimes does in music ensembles when people care deeply about what they're doing and the terms on which they come together to do it. In short, she left the group, and it took us more than a year to get things back on track. She wasn't a trained musician, so her sense of rhythm wasn't perfect, but she had more ki than anyone else I've ever played with. She had already been playing for about ten years when I first started, so I looked to her as an authority, though she wasn't officially our teacher. Rev. Tom was our teacher and director, but Audrey was nonetheless completely in charge of our group. If she 
said "Get in line," we got in line. Sometimes this made me feel browbeaten and infantilized, but I still got in line, because she knew what she was doing.

This photo shows her jumping while playing, and it exemplifies her tremendous ki and her ability to channel it. It reminds me of how much fun it was to play beside her: she was always, always directed outward, and completely in the moment, and aware of whoever she was playing with. She was a tyrant, but she was also one of the most generous musicians with whom I've ever played. With some of my taiko pals, I feel as if they're waiting for me to do something wrong, but Audrey had the ability to pull the best playing out of each of us by connecting. Playing with some of my taiko friends feels like being bullied: they push the tempo on purpose and simply expect everyone to follow, for instance. Audrey sometimes bullied me with words, but only in rehearsals, and when we played together she created a positive connection that drew the best out of me and pulled me up to the next level.

When I teach fieldwork courses, I often ask my students to write an essay about one of their research photos, to get them out of show-and-tell mode. A picture isn't worth a thousand words: it will tell you only as much as you demand of it, and if you demand only that it retell old stories, then that's all it will do. John and Malcolm Collier (1992, 99-115) suggest several ways to treat photography as a kind of social action and interaction. For instance, they encourage anthropologists to use photographs in interviews - that is, the researcher and the researched should literally look at photographs together and thus disrupt the interviewer-interviewee binary-to prompt people to talk about themselves, their environment, and the things most meaningful to them. As the Colliers put it, this shifts the very terms of the relationship, by asking people to be "expert guides" rather than "the subject of the interrogation" (106). It also resituates meaning from the image back into the person looking at it. Photographs aren't self-contained: they aren't objects complete unto themselves, though a heavy history of aestheticized assumptions encourages this idea. They demand to be read, and my reading of this photograph includes attention to the relationship I had with Audrey, to sadness over a friendship lost, to a discussion of what ki is and how it works, to the dynamics of pedagogy and learning.

\section{MOVING: THIS IS HOW THESE MOMENTS COME TOGETHER}

We shouldn't expect photographs to stand alone. After all, the stand-alone photograph is basically a throwback to art history and the odd ways that the practice of aestheticized photography has been wed to the history of painting: early photographers often evoked the moves and expectations of painterly praxis, including the expectation that "an" image should have the legs to stand on its own, alone, as an isolated moment. Why should that be? The image is a moment extracted from many moments. So maybe we shouldn't force it to be a single moment. Instead, let me 
show you an afternoon-the long, beautiful afternoon of August 4, 2007, at Gardena Buddhist Church, a Japanese American temple in California. I share that afternoon with you to explain why taiko players need to know how to do bon-odori, the group dances that are part of the Obon ritual. I use photography to try to show you what it was like, on that afternoon, for this taiko player to dance and dance and dance. I will need to show you quite a few photographs, and most aren't Kodak moments-they aren't perfectly composed or balanced or even memorable. But why should we insist that any of them be so? Instead, I suggest that looking at this series of photographs will teach you what it was like, on that afternoon, to be a taiko player who went to participate in bon-odori to move through what some Japanese Americans say is the heart of Japanese American taiko, even though you are moving to taiko rather than playing it. I don't yet want to give you an encyclopedia definition of Obon or bonodori. Both are touchstones throughout this book. Suffice it to say that these dances are both new and old, that they are always done in unison, and that it doesn't matter whether the people who dance them are good or not: the point is to participate. Obon is a kind of unintentional corrective to the SoCal multicultural festival. I don't offer it as more authentic; rather, it reflects the reality of existing Japanese American communities that are here, now, despite incarceration, despite out-marriage, despite the fact that the suburbs are the new Japantowns. Obon interfaces with the multicultural festival but is its vital cousin, reminding us that community is sometimes quite real and coherent and doesn't need to be stage-managed.

The dances are scheduled at the end the day, after you have presumably been at the temple for a while, probably watching and listening to taiko performances and buying and eating teriyaki, dango, spam musubi, gyoza, or shaved ice. It's five oclock, and people are gravitating toward the side street that's been closed to traffic, where white lines have been chalked onto the asphalt, concentric ovals a block long. If you're a kid, you went bobbing for goldfish and are probably carrying one around in a clear plastic bag. You've checked out the farmers' market. If you're a member of the temple's Buddhist Women's Association, you've been in high gear for several days and are now working at a food stall. If you're a member of the temple, you've been running into acquaintances and chatting.

Participating in an event often means looking at the backs of people's heads. Dancing means you're in motion and can't make the moments into a single moment. Participating means taking "bad" pictures-photographs that are blurry, unbalanced, cluttered, unposed. Coaesthetic witnessing forces a willingness to discard the aestheticized terms of good photography once and for all. You-the reader-must flip through these photos in a suspended act of waiting to dance (see video 3, montage of Obon and bon-odori at Gardena Buddhist Church, August 4, 2007, at http://wonglouderandfaster.com). Most were taken between dances. Each dance lasted about five minutes and the entire event about two hours. In between dances, things stopped for three or four minutes while a new drummer climbed up into the yagura or the MC made sure the right $\mathrm{CD}$ was in the PA system. Everyone 
waited, still on the white lines. We chatted with one another. People came into or went out of the dance circle. That's when I took pictures. There are no photographs here of dancing (because I was dancing), save one near the beginning of the sequence. The woman in it stands with her hands folded in prayer, slightly to the left of the white chalk line in the street. She and her dance companions wear matching white happi coats with red borders-they're all from the same temple. Her face is solemn; her expression suggests something internal. She's praying, or rather, her face and her hands and her stance all say that this is "Bon-odori Uta," the dance done at the beginning and again at the very end of the evening. The dance is prayer, stately and a bit slow, with the hands in and out of gassho: they weave and sway, pantomiming a fish swimming. Gassho is several things at once: the gesture of putting the hands together in prayer, a greeting, an expression of ritual understanding that a Buddhist frame has been created, reverence. My photograph shows the woman in prayer-her hands, her face, her body, her place in a line of people doing the same thing. It's a "good" photo. But its presence here means I wasn't in gassho, which isn't good at all.

\section{MOVING THROUGH THE IMAGE}

Documenting Japanese American drumming demands a new kind of visual ethnomusicology. I have offered a series of moves that folds the history of the colonial gaze into a mindful practice of seeing. It is impossible to do visual documentation of any kind without reenacting colonial and touristic traditions of looking. These acts of looking are unavoidably part of the way the way that we see and thus part of the way that anyone-including taiko players themselves-is forced to "see" taiko. I offer an unbeautiful, uncelebratory visual ethnomusicology that acknowledges the guiding, spectacularized effects of colonial surveillance on our ability to see yet deploys visual technologies to try to get inside the performance of alterity from the viewpoint of a participant. I thus offer a willfully conflicted yet mindful attempt to document taiko as an intervention in those economies.

Reaching for a time-out-of-time is perhaps necessary here. The defining gaze can't be undone, it seems. As Rey Chow $(1993,51)$ puts it, "Because [the] 'originary' witnessing is, temporally speaking, lost forever, the native's defiled image must act both as 'image' (history of her degradation) and as that witnessing gaze." The moment before being seen retreats and retreats. My book doesn't stand silently on the page: it shudders and blinks and jumps. I hope it pushes at how ethnomusicology has depended on critical moves that limit how we are able to think about performance - that is, how we are able to see performance, and thus to see the serious cultural work that performance does. I dance with the camera. Sometimes it's in my pocket and sometimes it's in my hand. My I/eye has many fields of vision. I am trying to see more than I can ever, really, see-yet the effort itself is the performative task that begs to be attempted. 